Supplement of Hydrol. Earth Syst. Sci., 22, 6435-6448, 2018

https://doi.org/10.5194/hess-22-6435-2018-supplement

(C) Author(s) 2018. This work is distributed under

the Creative Commons Attribution 4.0 License.

(c) (1)

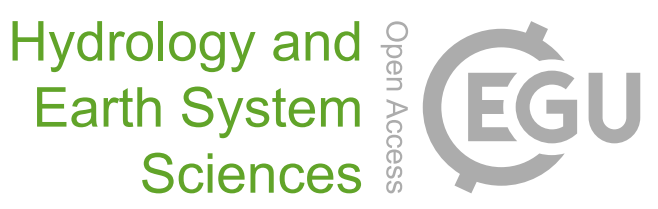

Supplement of

\title{
Using modelled discharge to develop satellite-based river gauging: a case study for the Amazon Basin
}

\section{Jiawei Hou et al.}

Correspondence to: Jiawei Hou (jiawei.hou@anu.edu.au)

The copyright of individual parts of the supplement might differ from the CC BY 4.0 License. 


\section{S1 Daily, 8-day and Monthly Performance of the MODIS and GFDS SGRs, and the Model}

We compared daily, 8-day and monthly performance of the MODIS and GFDS SGRs and the model in two river reaches in the lower channel of the Amazon River to evaluate the effect of temporal aggregation on prediction accuracy. The daily streamflow records were derived from Brazil's National Water Agency database by H.E. Beck (Princeton University, pers. comm.). To highlight temporal details, below we compared the different estimates for an arbitrary 13-month period (August, 2006 - August, 2007 for G32; June, 2006 - June, 2007 for G33). The daily and 8-day SGR predictions are noisy (Figure S1a, $b, d$ and e) as the GFDS signal is influenced by many factors such as the weak magnitude of the radiance received at the passive sensor, the changing scanning geometry, footprint size of each swath, and the path of the radiation through the atmosphere (Kugler and De Groeve, 2007), whereas the MODIS signal sometimes appears to be affected by cloud or aerosols. However, both MODIS and GFDS SGRs can reflect monthly and seasonal discharge dynamics reliably (Figure S1c and f).

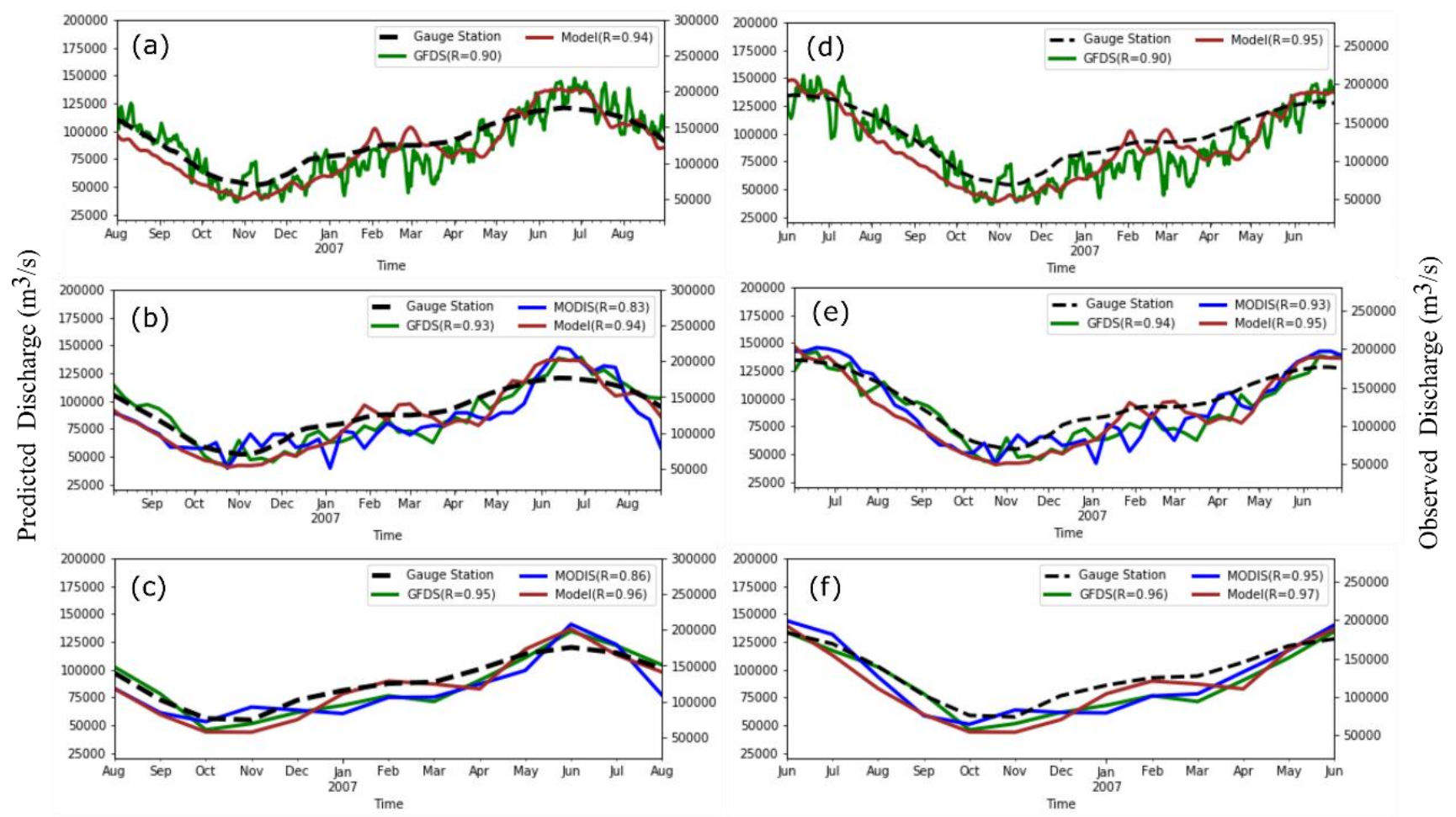

Figure S1 Comparisons between observations (right axis) from gauging stations (black dash) and river discharge estimates (left axis) derived using MODIS SGRs (blue line), GFDS SGRs (green line) and the W3 model (brown line) (top row: daily results; middle row: 8 day results; bottom row: monthly results; left column: gauge station $\mathrm{G} 32\left(3.06^{\circ} \mathrm{S}, 59.65^{\circ} \mathrm{W}\right)$; right column: gauge station $\mathrm{G} 33\left(1.92^{\circ} \mathrm{S}\right.$, $\left.55.51^{\circ} \mathrm{W}\right)$ 